\title{
Erratum to: Frequency of MDR 1-related p-gp overexpression in Greek Leishmania isolates
}

\author{
Johannes Austrup ${ }^{1} \cdot$ Pantelis Ntais $^{2} \cdot$ Vasiliki Christodoulou $^{3} \cdot$ Jean-Pierre Dedet $^{4}$. \\ Francine Pratlong ${ }^{4}$ Panagiotis Karanis ${ }^{1,5}$ - Maria Antoniou ${ }^{2}$
}

Published online: 19 June 2015

(C) Springer-Verlag Berlin Heidelberg 2015

Erratum to: Parasitol Res 113 (3): 1225-1232

DOI 10.1007/s00436-014-3761-8

Pantelis Ntais, Vasiliki Christodoulou, Jean-Pierre Dedet, Francine Pratlong, and Maria Antoniou have been added to the list of authors. These co-authors contributed equally to the work. The study was partially funded by EUgrant FP7261504 EDENext and is catalogued by the EDENext Steering Committee as EDENext120 (http://www.edenext.eu). The authors wish to thank Eleni Koutala, Ippokratis Messaritakis, Apostolos Mazeris and Eleni Svirinaki for technical assistance.

The online version of the original article can be found at http://dx.doi.org/ 10.1007/s00436-014-3761-8.

Johannes Austrup

johannesaustrup@gmail.com

1 Center of Anatomy, Institute II, Laboratory for Medical and Molecular Parasitology, Medical School, University of Cologne, Cologne, Germany

2 Laboratory of Clinical Bacteriology, Parasitology, Zoonoses and Geographical Medicine, Faculty of Medicine, University of Crete, Crete, Greece

3 Veterinary Services of Cyprus, Nicosia, Cyprus

4 University Montpellier 1, Faculty of Medicine, Laboratory of Parasitology-Mycology, Hospital University Centre (CHRU) of Montpellier and French National Reference Centre for Leishmaniases, CNRS 5290 - IRD 224 - University Montpellier 1\&2 (UMR “MIVEGEC"), Montpellier, France

5 National Research Center of Protozoan Diseases, Obihiro University for Agriculture and Veterinary Medicine, Hokkaido, Japan 